\title{
Reply to the Letter to the Editor. Endoleak after endovascular aortic repair and lumbar vertebral erosion
}

\author{
Federico Mancini • Andrea Ascoli-Marchetti • \\ Luca Garro · Roberto Caterini
}

Received: 23 October 2014 / Accepted: 22 January 2015/Published online: 26 February 2015

(C) The Author(s) 2015. This article is published with open access at Springerlink.com

We thank Bozzani and co-workers for their comments [1] regarding this case [2]. It has been emphasized that this type of endoprosthesis does not generally promote rupture. In fact, in the most recent international trial, the incidence of type II endoleak (i.e., abnormal persistent post-endovascular aneurysm repair (EVAR) filling of the aneurysm sac through one or more of the branch vessels) after infrarenal implantation of a polymer-filled endovascular prosthesis was reported to be $34 \%$ [3]; however, a significant increase in the diameter was documented in only one case $(0.7 \%)$. Moreover, ruptures did not result at 12-month follow-up but further observation has been recommended [4]. However, in this case the delay between implantation and the occurrence of an aneurysm was less than 1 year. We agree that in most cases the tamponade aortic rupture is determined by an endoleak or endotension. In this case, however, the aneurysm was extremely large (6.2-cm in diameter, Fig. 1), and this condition has been documented as a risk factor for rupture, including in well-positioned vascular endoprosthesis

Fig. 1 CT scan performed after EVAR procedure. The aneurysm was $>6 \mathrm{~cm}$ in diameter

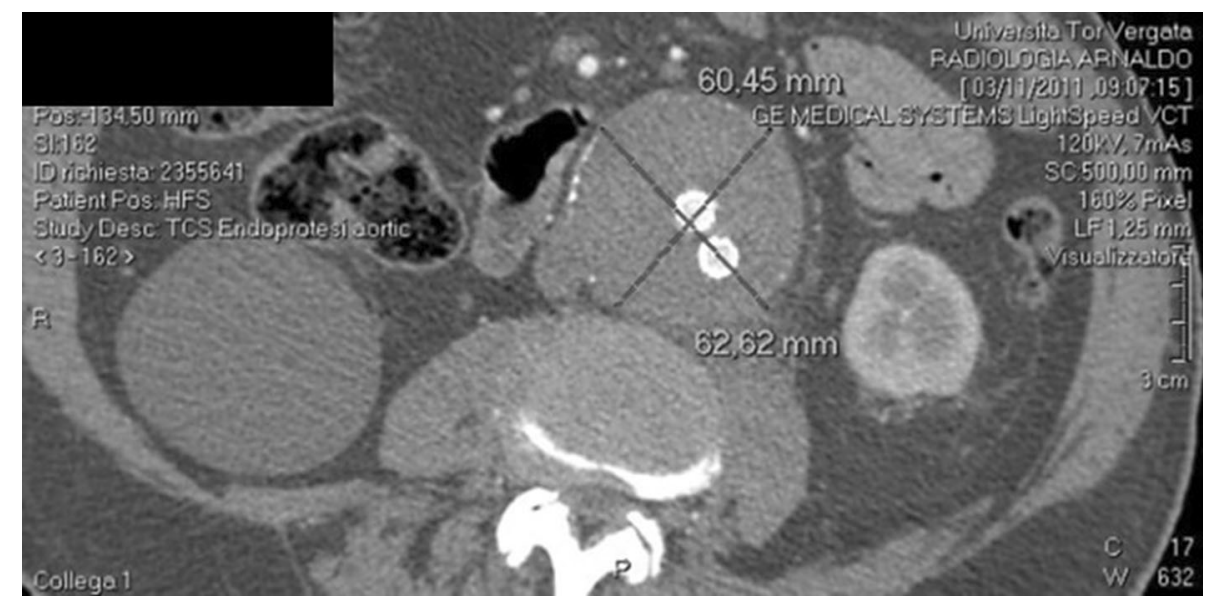

F. Mancini · A. Ascoli-Marchetti · L. Garro $(\bowtie) \cdot$ R. Caterini

University of Rome "Tor Vergata", Rome, Italy

e-mail: garro.luca@gmail.com 


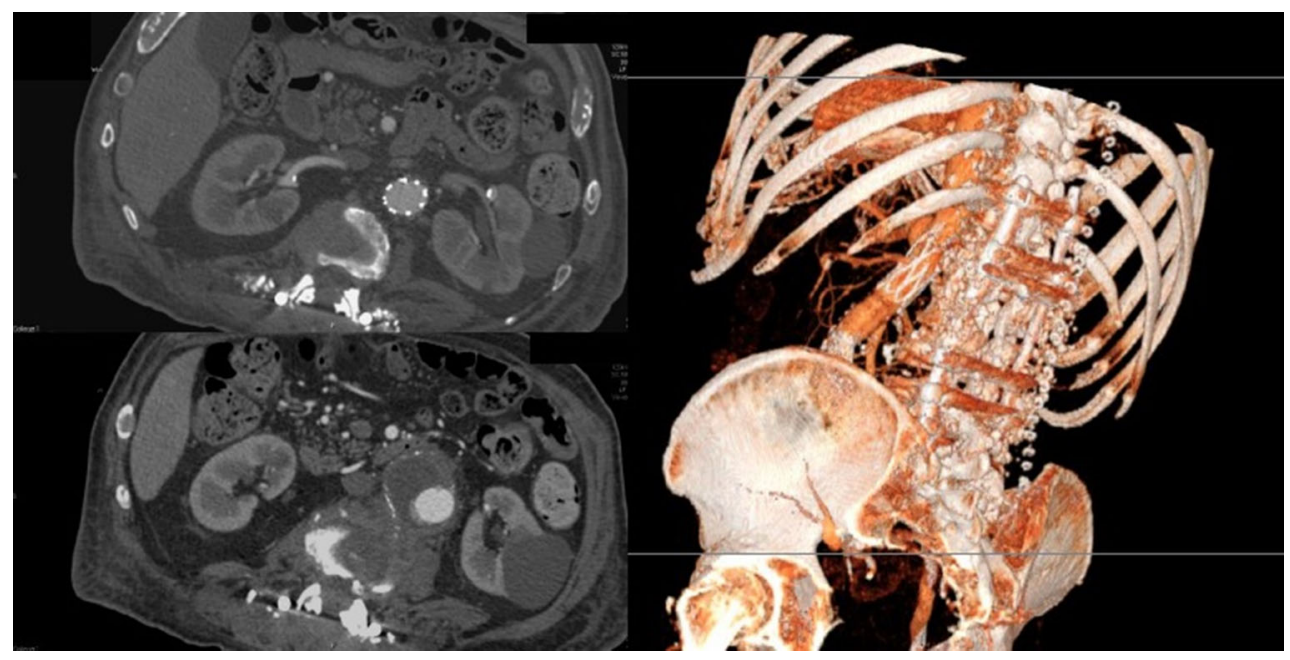

Fig. 2 CT scan performed after spinal surgery showing the absence of infra/suprarenal endoleak

[5]. A computed tomography (CT) scan performed after the spinal procedure did not reveal any signs of an endoleak or bleeding (Fig. 2).

Open Access This article is distributed under the terms of the Creative Commons Attribution License which permits any use, distribution, and reproduction in any medium, provided the original author(s) and the source are credited.

\section{References}

1. Bozzani A, Arici V, Ragni F, Argenteri A (2014) Endoleak after endovascular aortic repair and lumbar vertebral erosion. J Orthopaed Traumatol. doi:10.1007/s10195-014-0329-4

2. Mancini F, Ascoli-Marchetti A, Garro L, Caterini R (2014) Aseptic lysis L2-L3 as complication of abdominal aortic aneurysm repair. J Orthopaed Traumatol 15(4):291-294. doi:10.1007/ s10195-014-0308-9

3. Mehta M, Valdés FE, Nolte T, Mishkel GJ, Jordan WD, Gray B, Eskandari MK, Botti C; A Pivotal Clinical Study to Evaluate the Safety and Effectiveness of the Ovation Abdominal Stent Graft System Investigators (2014) One year outcomes from an international study of the Ovation Abdominal Stent Graft System for endovascular aneurysm repair. J Vasc Surg 59(1):65.e1-3-73.e1-3. doi:10.1016/j.jvs.2013.06.065

4. Keith CJ Jr, Passman MA, Gaffud MJ, Novak Z, Pearce BJ, Matthews TC, Patterson MA, Jordan WD Jr (2013) Comparison of outcomes following endovascular repair of abdominal aortic aneurysms based on size threshold. J Vasc Surg 58(6):1458-1466. doi:10.1016/j.jvs.2013.06.060

5. Greiner A, Schleimer K, Jalaie H, Gombert A, Jacobs MJ, Kalder J (2014) Late rupture after EVAR: a new trend? J Cardiovasc Surg (Torino) 55(2 Suppl 1):169-174 